\title{
Coverage and determinants of protective dose tetanus toxoid vaccine among postnatal women delivered at university of Gondar comprehensive specialized hospital, northwest Ethiopia, 2019
}

\author{
Dereje Nibret Gessesse ${ }^{\mathrm{a},{ }^{*}}$, Ayenew Engida Yismaw ${ }^{\mathrm{a}}$, Yazachew Engida Yismaw ${ }^{\mathrm{b}}$, \\ Tadesu Wondu Workneh ${ }^{\text {a }}$ \\ ${ }^{a}$ Department of Clinical Midwifery, School of Midwifery, College of Medicine and Health Sciences and Comprehensive Specialized Hospital, University of Gondar, \\ Gondar, Ethiopia \\ ${ }^{\mathrm{b}}$ Department of Pharmacology, School of Health Science, College of Medicine and Health Sciences, Bahr Dar University, Bahr Dar, Ethiopia
}

\section{A R T I C L E I N F O}

\section{Keywords:}

Postnatal women

Protective dose

Northwest Ethiopia

Tetanus toxoid vaccine

\begin{abstract}
A B S T R A C T
Background: Even though there have been tremendous strides globally in reducing the burden of tetanus, neonatal deaths due to tetanus have reported annually, and most deaths occur in sub-Saharan Africa which accounts for nearly half of the global neonatal mortality by tetanus. Immunization of pregnant women or women of childbearing age with at least two doses of tetanus toxoid is estimated to reduce mortality from neonatal tetanus by $94 \%$. Despite its importance, immunization programs are suboptimal in Ethiopia, where more than $85 \%$ of the population have resides in rural districts. Therefore, this study has been used to determine the coverage and determinants of protective dose tetanus vaccine among postnatal women and design a strategy to maximize the service.

Methods: Institution-based cross-sectional study was conducted from December 20-June 20, 2019. The sample was taken using a systematic random sampling method. To collect data from the study participants, a semistructured interviewer-administered and pre-tested questionnaire was used. The data were entered into Epi info version 7.0 and then exported to SPSS version 20.0 for analysis. Logistic regressions analysis was conducted and the level of statistical significance was determined by a p-value of less than 0.05 .

Results: The proportion of immunization with Tetanus toxoid protective dose was 69.8\% (95\% CI: 65.2-74.0). Urban residence (AOR $=3.626$, 95\%CI: 1.510-8.707), husband's having secondary education (AOR = 7.397, 95\%CI: 1.873-29.211), husband's having tertiary education (AOR $=9.539$, 95\%CI: 2.277-39.969), women stated that the provision of TT vaccine service was good (AOR $=3.978,95 \% \mathrm{CI} 1.303-12.146$ ) and mother stated health care workers who provide TT vaccine were good in their behavior (AOR $=4.259,95 \%$ CI: 1.913-9.484) were factors influencing utilization of TT protective dose immunization.

Conclusion: The proportion of TT protective dose immunization in the study area was found to be low. Being Urban residence, secondary and tertiary levels of the husband's educational status, women who stated that 'the provision of TT vaccine service was good' and "health care workers who provide TT vaccine were good in their behavior were statistically significant factors influencing TT protective dose immunization. Thus, it is better to strengthening education and empowering women to enhance vaccine utilization. Besides, promoting husband's education and creating community awareness particularly rural residents are better options to increase utilization of TT protective dose vaccine.
\end{abstract}

\section{Introduction}

Tetanus is a bacterial disease caused by Clostridium tetanus in individuals without protective circulating antibodies. Maternal tetanus infection occurs after abortion, miscarriages, or unhygienic delivery procedures, whereas neonatal tetanus infection typically occurs after

\footnotetext{
* Corresponding author.

E-mail addresses: dnibret62@gmail.com, dnibret62@gmail.com (D.N. Gessesse), ayenewe07@gmail.com (A.E. Yismaw), yachewable@gmail.com (Y.E. Yismaw), tadesuwondu24@gmail.com (T.W. Workneh).
} 
delivery via umbilical stump. ${ }^{1,2}$ Death from tetanus disease is protected by at least two doses of tetanus toxoid immunization of pregnant women or women of reproductive age., Even though there have been tremendous strides globally in reducing the burden of tetanus, 25,000 unnecessary neonatal deaths reported annually, ${ }^{5}$ and most deaths occur in sub-Saharan Africa which accounts for nearly half of the global neonatal mortality by tetanus. ${ }^{6}$ In Somalia, South Sudan, Afghanistan, and Kenya, the highest rates of neonatal tetanus mortality were recorded (1000 deaths per 100,000 populations). Ethiopia is one of amongst 35 countries supported by UNICEF for tetanus toxoid vaccine and is reported to be yet not validated state for maternal and neonatal tetanus elimination. ${ }^{7}$ Immunization of pregnant women or women of childbearing age with at least two doses of tetanus toxoid (TT) is estimated to reduce mortality from neonatal tetanus by $94 \% .{ }^{3}$ Despite its importance, immunization programs are suboptimal in many parts of the world, especially in the least developed districts of low-income countries. ${ }^{1}$

A community-based household survey conducted in Lao People's Democratic Republic showed that the utilization of protective TT dose was $79.7 \%{ }^{8}$ National Family Health Survey in Indian also reported that protective TT dose coverage among mothers who attend antenatal care was $68 \% .{ }^{9}$ A cross-sectional study conducted in Ibadan, Nigeria revealed that about $81.1 \%$ of mothers were taken at least two doses of TT vaccine. ${ }^{10}$

Ethiopian demographic and health survey (EDHS 2016) report showed that the proportion of TT protective dose immunization was 49\%. ${ }^{11}$ A systematic review and Meta-analysis done on TT protective dose immunization in Ethiopia is also showed that about $52.6 \%$ of women were vaccinated during pregnancy at least twice. ${ }^{12} \mathrm{~A}$ community-based cross-sectional study done on immunization dropout rate in Debrebirhan Town, AmharaRegion, Northern Ethiopia was found to be $72.3 \% .^{13}$ A different study conducted in different segments of Ethiopia such as in Errer District, Somali Regional State, Eastern Ethiopia (51.8\%), ${ }^{14}$ Tselemti District, Ethiopia (61.8\%), ${ }^{15}$ Damboya Woreda, Kembata Tembaro Zone, SNNP, Ethiopia (72.5\%), ${ }^{16}$ DebreTabor town, Ethiopia (56.2\%), ${ }^{17}$ Dukem Town, Eastern Ethiopia $(39.2 \%),{ }^{18}$ and Hawzen, Eastern Zone of Tigray, Ethiopia $(40.2 \%)^{19}$ showed that none of those studies hits the target standard endorsed by WHO.

Different studies studied in different parts of Ethiopia and some other countries reported different risk factors that influence TT protective dose immunization. In many studies, as parents' educational level increases compared to none educated, the utilization rate of immunization with TT protective dose decreases. ${ }^{12,16-18,20-22}$ Another variable significantly associated with TT protective dose utilization was the number of antenatal care visits. ${ }^{12,16-19,23,24}$ Also, other variables such as residence, ${ }^{10,14,15,23}$ center to far, ${ }^{12,16,18,21}$ lack of knowledge on the benefit, ${ }^{21,22,24,25}$ health staff attitude, ${ }^{26}$ perceived good quality of service, ${ }^{17}$ owing TV in the household, ${ }^{18}$ joint health decision, ${ }^{16}$ low income, ${ }^{20,21}$ occupational status ${ }^{22}$ were significantly associated with a utilization rate of TT protective dose vaccine. As our search is concerned, there is no study conducted on the study area about a protective dose of tetanus vaccine. So, this study was aimed to assess the coverage and determinants of protective dose of tetanus vaccine among postnatal women delivered at University of Gondar comprehensive specialized hospital in northwest part of Ethiopia which serves the population coming from different climate conditions like the high up, the coral and Sumi-desert areas.

\section{Methods}

An institution-based cross-sectional study design was conducted from December 20-June 20, 2019 among postnatal women delivered at University of Gondar comprehensive specialized hospital. University of Gondar comprehensive specialized Hospital is located $727 \mathrm{~km}$ far from Addis Ababa (the capital city of Ethiopia). University of Gondar comprehensive specialized hospital is one of the largest tertiary teaching hospitals found in Ethiopia especially Amhara region and serving more than seven million people coming from the hottest and coldest climatic conditions of the northwest part of the country. It provides maternity health care services for women coming from Amhar, Tigray, and Benshangul Gumuz regions. All mothers who gave birth at University of Gondar comprehensive specialized hospital were included in the study. The proportion of mothers receiving any of the following recorded TT doses or verbally stated as "I have taken the vaccine" was described as TT protective dose vaccinated ${ }^{1}$ : during the pregnancy, two TT injections $s^{2}$; two or three doses, the last dose within three years ${ }^{3}$; three or more shots, the last within five years of birth ${ }^{4}$; four or more vaccines, the last one within ten years after birth ${ }^{5}$; five doses or more at any point before birth.

Variables, socio-demographic (age, residence, educational status, marital status, and occupation), health and health-related factors (number of ANC visit, Distance from the health facility, Home visit of HEWs, Availability of vaccine), and Economic factors (Income, Employment, and Media access like TV) were assessed. The sample size for the study was determined by using single population proportion formula by considering, $56.2 \%$ of the proportion of protective TT does immunization, 95\% confidence level, and 5\% margin of error. $n=z^{2} p$ $(1-\mathrm{p}) / \mathrm{d}^{2} ;(1.96)^{2}(0.562)(0.438) /(0.05)^{2}=379 ;$ Where; $\mathrm{n}=$ required sample size, $\mathrm{z}=$ confidence level at $95 \%$ (at standard value of 1.96 ), $\mathrm{p}=$ estimated proportion $(56.2 \%)$ and $d=$ margin of error at $5 \%$ (standard value of 0.05 ). By considering $10 \%$ none response rate the final sample size was 417 .

The sample was taken using a systematic random sampling method. The total delivery in the last two months at university of Gondar comprehensive specialized hospital was 1922 and then we divided this by calculated sample size and gave as $1922 / 417=4.6=5$. So, study participants were taken every fifth interval. The first participant was selected using a lottery method.

Data were collected from the study participants at postnatal clinic during discharge to home with a semi-structured interviewer-administered and pre-tested questionnaire. The questionnaire was adapted from different literatures with modifications to the local context to make it clear and understandable. The data were collected by four health care providers and one supervisor. The principal investigators were supervised the overall process and solve if any problem faced.

Then, the collected data were cleaned, coded, and entered into Epiinfo version 7 then exported to SPSS version 20 software package for further analysis. Frequencies and cross-tabulations were used to summarize descriptive statistics. The data were presented by texts and tables. Variables were fitted to multivariable logistic regression using a backward likelihood ratio method. Both COR and AOR were measured to demonstrate the strength of the association with the corresponding 95\%CI. Besides, model fitness was checked using the Hosmer and Lemeshow goodness of a fit test, and the model test P-value was found to be 0.55 . Finally, a statistically significant association of variables was claimed based on AOR with its $95 \% \mathrm{CI}$ and p-value $<0.05$.

\section{Result}

\subsection{Socio-demographic characteristics}

A total of 417 women were successfully interviewed, making a $100 \%$ response rate. The median age of the participants was 28 years with six years deviation $( \pm 6 \mathrm{SD}$ ). The average monthly income of the household was about four thousand one hundred eighty-one Ethiopian birr with $( \pm 2981 S D)$. A majority (62.1\%) of the respondents was an urban residence and about $76 \%$ of them were Orthodox Christianity follower. About one-fourth of the participants were can not read and write. Most $(92.6 \%)$ of the women were married and more than one-third of their husband occupation were government employees. About $30.5 \%$ of the husband's educational status was college and above. More than half of the participants had no radio/Television in their home (Table 1). 
Table 1

Socio-demographic characteristics of women in University of Gondar comprehensive specialized hospital, Northwest Ethiopia, 2019 ( $\mathrm{n}=417)$.

\begin{tabular}{|c|c|c|c|}
\hline Variables & Category & Frequency & $\begin{array}{l}\text { Percent } \\
(\%)\end{array}$ \\
\hline \multirow[t]{3}{*}{ Age } & $15-19$ & 28 & 6.7 \\
\hline & $20-34$ & 306 & 73.4 \\
\hline & $35-49$ & 83 & 19.9 \\
\hline \multirow[t]{5}{*}{ Maternal education } & Cannot read \& write & 108 & 25.9 \\
\hline & can read \& write & 50 & 12.0 \\
\hline & elementary grade ${ }^{1-8}$ & 79 & 18.9 \\
\hline & Secondary grade ${ }^{9-12}$ & 98 & 23.5 \\
\hline & $\begin{array}{l}\text { Tertiary (college \& } \\
\text { above) }\end{array}$ & 82 & 19.7 \\
\hline \multirow[t]{2}{*}{ Residence } & Urban & 259 & 62.1 \\
\hline & Rural & 158 & 37.9 \\
\hline \multirow[t]{5}{*}{ Mother's occupation } & Housewife & 268 & 64.3 \\
\hline & Government employee & 84 & 20.1 \\
\hline & Merchant & 36 & 8.6 \\
\hline & Daily labourer & 19 & 4.6 \\
\hline & Student & 10 & 2.4 \\
\hline \multirow[t]{3}{*}{ Religion } & Orthodox & 319 & 76.5 \\
\hline & Protestant & 23 & 5.5 \\
\hline & Muslim & 75 & 18.0 \\
\hline \multirow[t]{3}{*}{ Marital status } & Married & 386 & 92.6 \\
\hline & Divorced & 22 & 5.3 \\
\hline & Others $^{\mathrm{a}}$ & 9 & 2.1 \\
\hline \multirow[t]{5}{*}{ Husband occupation } & Government employee & 144 & 34.5 \\
\hline & Farmer & 34 & 8.2 \\
\hline & Merchant & 123 & 29.5 \\
\hline & Daily laborer & 106 & 25.4 \\
\hline & Student & 10 & 2.4 \\
\hline \multirow{5}{*}{$\begin{array}{l}\text { Husband educational } \\
\text { status }\end{array}$} & Cannot read \& write & 53 & 12.7 \\
\hline & can read \& write & 68 & 16.3 \\
\hline & elementary grade ${ }^{1-8}$ & 61 & 14.6 \\
\hline & Secondary grade ${ }^{9-12}$ & 108 & 25.9 \\
\hline & $\begin{array}{l}\text { Tertiary (college \& } \\
\text { above) }\end{array}$ & 127 & 30.5 \\
\hline \multirow[t]{2}{*}{ Radio/TV } & No & 222 & 53.2 \\
\hline & Yes & 195 & 46.8 \\
\hline
\end{tabular}

${ }^{\mathrm{a}}$ Windowed and never married.

\subsection{Obstetric and health service-related factors}

More than half (51.6\%) and about one-third (33\%) of the women were multiparas and primipara respectively. Nearly three-fourths $(73.1 \%)$ of respondents were started the first visit in their second trimester and large segments (89.2\%) of the participants "stated that the provision of TT vaccine service was good". Most (71.3\%) of the women respondents had planned to have more children in the future. A large segment $(60.4 \%)$ of women got the information about the TT vaccination from the health caregiver. Around $94 \%$ of the respondents had trust in the TT service given at the institution. Most (82.3\%) of the pregnancy was planned. More than half (53.7\%) of respondents were aware of the purpose of taking TT vaccine for the prevention of both newborn and maternal tetanus. About $80 \%$ of women said that "health care workers who provide TT vaccine were good in their behavior" (Table 2).

\subsection{Proportion of immunization with TT vaccine}

The study showed that the proportion of immunization with a protective dose of Tetanus toxoid vaccine among postnatal mothers was found to be $69.8 \%$ (95\% CI: $65.2-74.0$ ).

\subsection{Factors associated with tetanus toxoid protective dose immunization}

The results of the bi-variable analysis showed that variables: age, parity, mother stated TT vaccine service as good or not good, mother stated health care provider who provides TT vaccine as good or not good, trust on the service given, planned pregnancy, respected care, the
Table 2

Obstetric and health service-related factors among mothers in University of Gondar comprehensive specialized hospital, Northwest Ethiopia, 2019 (n = 417).

\begin{tabular}{llll}
\hline Variables & Category & Frequency & $\begin{array}{l}\text { Percent } \\
\text { (\%) }\end{array}$ \\
\hline Parity & 1 & 139 & 33.3 \\
& $2-4$ & 215 & 51.6 \\
& $\geq 5$ & 63 & 15.1 \\
Timing of first visit & First trimester & 112 & 26.9 \\
& Second trimester & 305 & 73.1 \\
Mother stated provision of TT & and above & & \\
vaccine quality was & Good & 372 & 89.2 \\
Mother stated Behavior of health & Not good & 45 & 10.8 \\
care workers who provide TT & Good & 334 & 80.1 \\
vaccine & Not good & 83 & 19.9 \\
Purpose of taking TT vaccination & For the mother & 14 & 3.4 \\
& For the newborn & 92 & 22.1 \\
& For both & 224 & 53.7 \\
Trust on the service given & Not known & 87 & 20.9 \\
Planned pregnancy & Poor & 24 & 5.8 \\
& Good & 393 & 94.2 \\
Source of information & Yes & 343 & 82.3 \\
& No & 74 & 17.7 \\
Want more children & Health caregiver & 252 & 60.4 \\
& Neighbor & 5 & 1.2 \\
& TV/Radio & 160 & 38.4 \\
& Yes & 120 & 28.7 \\
& No & 297 & 71.3 \\
\hline
\end{tabular}

purpose of taking TT vaccine, timing of the first visit, wanting more children, husbands educational status, owing Television or Radio, maternal educational status and residence were associated with TT protective dose immunization at a $20 \%$ level of significance. The final multivariable logistic regression model showed that variables such as clients "stated that the provision of TT vaccine service was good", clients said that "health care workers who provide TT vaccine were good in their behavior", Husband educational status, and residence were significant determinants of tetanus toxoid vaccination at a $5 \%$ level of significance. Those women who reside in urban areas were $\mathbf{3 . 6 3}$ times more likely to have TT protective dose immunization as compared to their counterparts (AOR $=3.626$, 95\%CI: $1.510-8.707$ ). Women whose Husbands' educational status of secondary ${ }^{9-12}$ and college and above were $\mathbf{7 . 4 0}$ and $\mathbf{9 . 5 4}$ more likely took TT protective dose immunization as compared to never attended (AOR $=7.397,95 \% \mathrm{CI}$ : $1.873-29.211$ ) $(\mathrm{AOR}=9.539,95 \% \mathrm{CI}: 2.277-39.969)$ respectively. The odds of TT protective dose immunization were $\mathbf{3 . 9 8}$ times higher among mothers who stated that the provision of TT vaccine service was good" than their counterparts (AOR $=3.978,95 \%$ CI 1.303-12.146). The odds of TT protective dose immunization were 4.26 times higher among mothers said that "health care workers who provide TT vaccine were good in their behavior" than their counterparts (AOR $=4.259,95 \% \mathrm{CI}$ : 1.913-9.484) (Table 3).

\section{Discussion}

This study showed that the proportion of Tetanus toxoid protective dose vaccine utilization among postnatal mothers found to be $69.8 \%$ (95\% CI: 65.2-74.0). This finding is in line with the study done in Rural North India $(68 \%),{ }^{9}$ and Damboya Woreda, Kembata Tembaro Zone, SNNP, Ethiopia (72.5\%). ${ }^{16}$ However, the magnitude of this result is higher as compared to the study conducted in 2016 Ethiopian demographic health survey (EDHS) (49\%), ${ }^{11}$ a systematic review and meta-analysis in Ethiopia (52.6\%), ${ }^{12}$ North-West Nigeria $(23.6 \%),{ }^{25}$ Peshawar (65\%) and (49.9\%), ${ }^{21,27}$ and studies done at deferent segments of Ethiopia such as Dukem Town, Eastern Ethiopia (39.2\%), ${ }^{18}$ Errer District, Somali Regional State, Eastern Ethiopia (51.8\%), ${ }^{14}$ Northern Ethiopia (56.2\%), ${ }^{17}$ and Hawzen, Eastern Zone of Tigray, 
Table 3

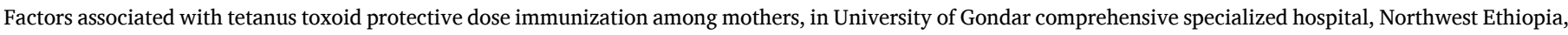
2019 ( $\mathrm{n}=417)$.

\begin{tabular}{|c|c|c|c|c|c|c|}
\hline \multirow{2}{*}{\multicolumn{2}{|c|}{ Variables }} & \multirow[t]{2}{*}{ Category } & \multicolumn{2}{|c|}{ TT protective dose } & \multirow[t]{2}{*}{ Crude Odds Ratio 95\% CI } & \multirow[t]{2}{*}{ Adjusted Odds Ratio 95\% CI } \\
\hline & & & Yes $(\%)$ & No (\%) & & \\
\hline \multirow{3}{*}{\multicolumn{2}{|c|}{ Age }} & $15-19$ & 13 & 15 & $0.632(0.267-1.495)$ & - \\
\hline & & $20-34$ & 230 & 76 & $2.207(1.329-3.664)$ & - \\
\hline & & $35-49$ & 48 & 35 & 1 & \\
\hline \multirow{3}{*}{\multicolumn{2}{|c|}{ Parity }} & 1 & 64 & 75 & 1 & \\
\hline & & $2-4$ & 192 & 23 & $9.783(5.666-16.890)$ & - \\
\hline & & $\geq 5$ & 35 & 28 & $1.465(0.805-2.665)$ & - \\
\hline \multirow{2}{*}{\multicolumn{2}{|c|}{ Maternal saying about provision of TT vaccine quality was ${ }^{\mathrm{b}}$}} & Good & 246 & 80 & $4.160(2.117-8.177)$ & $3.978(1.303-12.146)^{*}$ \\
\hline & & Not good & 17 & 23 & 1 & 1 \\
\hline \multirow{2}{*}{\multicolumn{2}{|c|}{$\begin{array}{l}\text { Maternal saying about behavior of health care workers who } \\
\text { provide TT vaccine were }{ }^{c}\end{array}$}} & Good & 249 & 76 & $3.116(1.875-5.180)$ & $4.259(1.913-9.484)^{* *}$ \\
\hline & & Not good & 41 & 39 & 1 & 1 \\
\hline \multirow{2}{*}{\multicolumn{2}{|c|}{ Trust on the service given }} & Not good & 11 & 12 & $3.093(1.322-7.238)$ & \\
\hline & & Good & 275 & 97 & 1 & \\
\hline \multirow{2}{*}{\multicolumn{2}{|c|}{ Planned pregnancy }} & Yes & 255 & 88 & $3.059(1.825-5.126)$ & $2.242(0.886-5.673)$ \\
\hline & & No & 36 & 38 & 1 & 1 \\
\hline \multirow{2}{*}{\multicolumn{2}{|c|}{ Perceived respected care }} & Not good & 35 & 25 & $2.133(1.200-3.792)$ & - \\
\hline & & Good & 227 & 76 & 1 & \\
\hline \multirow{4}{*}{\multicolumn{2}{|c|}{ Purpose of taking TT vaccination }} & For the mother & 10 & 4 & $4.516(1.307-15.602)$ & - \\
\hline & & For the newborn & 65 & 27 & $4.349(2.322-8.146)$ & - \\
\hline & & For both & 185 & 39 & $8.569(4.903-14.977)$ & - \\
\hline & & Not known & 31 & 56 & 1 & \\
\hline \multirow{2}{*}{\multicolumn{2}{|c|}{ Timing of first visit }} & First trimester & 82 & 19 & $1.866(1.064-3.271)$ & - \\
\hline & & Second and third trimester & 192 & 83 & 1 & \\
\hline \multirow{2}{*}{\multicolumn{2}{|c|}{ Want more children }} & No & 77 & 42 & 1 & \\
\hline & & Yes & 213 & 84 & $1.383(0.879-2.175)$ & \\
\hline \multirow[t]{5}{*}{ Husband educational status } & Cannot read\& write & & 22 & 31 & 1 & 1 \\
\hline & Can read\& write & & 36 & 32 & $1.585(0.768-3.272)$ & $1.897(0.575-6.259)$ \\
\hline & Primary $^{1-8}$ & & 40 & 21 & $2.684(1.255-5.739)$ & $2.749(0.756-9.991)$ \\
\hline & Secondary ${ }^{9-12}$ & & 88 & 20 & $6.200(2.985-12.877)$ & $7.397(1.873-29.211) *$ \\
\hline & Tertiary (college \&above) & & 105 & 22 & $6.725(3.293-13.733)$ & $9.539(2.277-39.969)$ * \\
\hline \multirow[t]{2}{*}{ Owing Radio/TV } & No & & 148 & 74 & 1 & \\
\hline & Yes & & 143 & 52 & $1.375(0,901-2.098)$ & - \\
\hline \multirow[t]{5}{*}{ Maternal education } & Cannot read\& write & & 50 & 58 & 1 & \\
\hline & Can read\& write & & 34 & 16 & $2.465(1.219-4.986)$ & - \\
\hline & Primary ${ }^{1-8}$ & & 63 & 16 & $4.567(2.346-8.894)$ & - \\
\hline & Secondary ${ }^{9-12}$ & & 78 & 20 & $4.524(2.434-8.410)$ & - \\
\hline & Tertiary (college \&above) & & 66 & 16 & $4.785(2.462-9.298)$ & - \\
\hline \multirow[t]{2}{*}{ Residence } & Urban & & 212 & 47 & $4.511(2.894-7.032)$ & $3.626(1.510-8.707)$ * \\
\hline & Rural & & 79 & 79 & 1 & 1 \\
\hline
\end{tabular}

* Indicated significance at p-value 0.05.

$* *$ indicated significance at p-value 0.001 .

NB: ${ }^{b}$ It was simply asked a single question that 'how did you rate the quality of TT vaccine provided and.

c 'how did you rate the behavior of the health care providers' the participants were respond as 'good and not good'.

Ethiopia (40.2\%). ${ }^{19}$ This discrepancy may be due to the time variation, the study setting in which most of the previous studies were conducted as a community based. In addition, awareness about the vaccine has increased with the advancement of technologies like social media and other sources of information.

On the other hand, This finding is lower than the findings conducted in Lahore, Punjab (90.47\%), ${ }^{20}$ Vientiane, Lao People's Democratic Republic $(79.7 \%),{ }^{8}$ Ibadan, Nigeria $(81.1 \%),{ }^{10}$ and Ghana $(82.6 \%) .{ }^{28}$ The difference might be because of the difference in the study population in terms of culture, health-seeking behavior, health care coverage, economic and infrastructural access.

The finding of this study showed that the women who reside in urban were $\mathbf{3 . 6 3}$ times more likely to take TT protective dose immunization as compared to their counterparts. This result is supported by the findings conducted in Errer District, Somali Regional State, Eastern Ethiopia, ${ }^{14}$ and Tselemti, Ethiopia. ${ }^{15}$ This might be due to mothers residing in the urban may have more information, easily access health care services nearby, which may increase awareness about TT immunization and utilization than mothers with a rural residence.

Women whose Husbands' educational status being secondary (grade 9-12) and tertiary (college \& above) were $\mathbf{7 . 4 0}$ and $\mathbf{9 . 5 4}$ more likely to take TT protective dose immunization as compared to cannot read and write respectively. This finding is supported by the study done in Lahore,
Punjab, $^{20}$ a systematic review and meta-analysis, Ethiopia, ${ }^{12}$ and Damboya Woreda, Kembata Tembaro Zone, SNNP, Ethiopia. ${ }^{16}$ This might be because an educated husband has greater awareness about the vaccine and support his wife to utilize the vaccine. Education also increases overall awareness, including the use of an individual's health and health care.

The finding of this study also revealed that women who stated that 'the provision of TT vaccine service was good' was the influencing factor to TT protective dose vaccine utilization among postnatal mothers. Thus, the odds of TT protective dose immunization were 3.98 times higher among mothers who stated that 'the provision of TT vaccine service was good' than their counterparts. This finding is supported by the study conducted in DebreTabor town, northern Ethiopia, ${ }^{17}$ Hispanic and Houston, Texas, ${ }^{29}$ Kenya, ${ }^{30}$ and Dormaa, Ghana. ${ }^{31}$ This suggested that regardless of the actual quality of service offered, merely a customer's impression of the quality of service matters receiving valid TT vaccination.

Finally, this study also showed that the women considering that "health care workers who provide TT vaccine were good in their behavior" was a factor greatly affecting the utilization of TT protective dose vaccine. Hence, the odds of TT protective dose immunization were 4.26 times higher among mothers considering that "health care workers who provide TT vaccine were good in their behavior" than those 
considering that "health care workers who provide TT vaccine were not good in their behavior". Mothers who got the service from health staff with bad behavior were less likely to utilize TT protective dose. ${ }^{26}$ This is indicated that, regardless of health service provider's real behavior, simply customer perception of health service providers' behavior issues receiving valid TT vaccination.

\section{Conclusion}

The proportion of TT protective dose vaccine utilization among mothers in the study area was found to be low. Being urban residency, being a secondary and above level of husband's educational status, women who stated that 'the provision of TT vaccine service was good' and "health care workers who provide TT vaccine were good in their behavior" were statistically significant factors influencing TT protective dose vaccine utilization. Thus, strengthening education, providing compassionate \&respectful care for the women, and providing quality care service is better to increase TT protective dose vaccine utilization. Besides, promoting husband's education and creation community awareness particularly rural residents are better options to increase utilization of TT protective dose vaccine.

\section{Declaration of competing interest}

The authors declare no competing interests.

\section{Acknowledgment}

We would like to thank study participants for their patience and data collectors. Our gratitude is also great to University of Gondar for providing ethical clearance for conducting this study.

$\begin{array}{ll}\text { Abbreviations } \\ \text { AOR } & \text { Adjusted Odds Ratio } \\ \text { CI } & \text { Confidence Interval } \\ \text { COR } & \text { Crude Odds } \\ \text { TT } & \text { Tetanus toxoid } \\ \text { SD } & \text { Standard Deviation } \\ \text { ANC } & \text { Antenatal Care } \\ \text { SSNP } & \text { southern nations, nationalities and peoples }\end{array}$

Funding

The author(s) received no specific funding for this work.

\section{Availability of data and materials}

The dataset analyzed during the current study will be available from the corresponding author on reasonable request.

\section{Ethics approval and consent to participate}

The ethical clearance letter was obtained from an ethical review committee of the school of midwifery on behalf of the Institutional Review Board of University of Gondar, College of medicine and health sciences. Then the participants of the study were informed about the purpose of the study, the importance of their participation, and their rights. Participants were told to have a right to refuse participation and also they can withdraw at any time during the interview. Any information given from participants was kept confidential and the data were kept anonymous. Finally, verbal informed consent was obtained before data collection.

\section{Consent for publication}

Not applicable.

\section{Authors' contributions}

All authors contributed to data analysis, drafting or revising the article, gave final approval of the manuscript to be published, and agree to be accountable for all aspects of the work.

\section{References}

1 World health organization, Who. Tetanus vaccines: WHO position paper - february 2017Weekly epidemiological record. WHOI. 2017;(6):53-76.

2 Thwaites CL, Nicholas J, Beeching F, Charles R, Newton M. Maternal and neonatal tetanus. Lancet. 2017;385(9965):362-370.

3 Blencowe H, Lawn J, Vandelaer J, Roper M, Cousens S. Tetanus toxoid immunization to reduce mortality from neonatal tetanus. Int J Epidemiol. 2010;39:1102-109.

4 Demicheli V, Barale A, Rivetti A. Vaccines for Women for Preventing Neonatal Tetanus ( Review ). 2015.

5 Njuguna HN, Yusuf N, Raza AA, Ahmed B, Tohme RA. Progress toward maternal and neonatal tetanus elimination - worldwide. 2000;69(17):515-520, 2018. 2020.

$6 \mathrm{Kyu} \mathrm{HH}$, Mumford JE, Stanaway JD, et al. Mortality from Tetanus between 1990 and 2015 : Findings from the Global Burden of Disease Study. 2015:1-17, 2017.

7 Unicef P. Maternal and Neonatal Tetanus Elimination Initiative Pampers UNICEF 2010 Campaign Launch. 2010.

8 Masunoa Kanako, Duangpachan Xaysomphoob AP, Somthana Douangmalac CK. Scaling up interventions to eliminate neonatal tetanus : factors associated with the coverage of tetanus toxoid and clean deliveries among women in Vientiane. Lao PDR. Vaccine. 2009;27:4284-4288.

9 Singh A, Pallikadavath S, Ogollah R, Stones W. Maternal tetanus toxoid vaccination and neonatal mortality in Rural North India. PloS One. 2012;7(11).

10 Orimadegun AE, Orimadegun BE, Bamgboye EA, Davis R, Cochi S, Rees H. Supplement article Non-protective immunity against tetanus in primiparous women and newborns at birth in rural and urban settings in. Pan Afr Med J. 2017;27(Supp 3): 23-28.

11 Central statistical agency/CSA/Ethiopia and ICF. Ethiopia Demographic and Health Survey. Addis Ababa, Ethiopia, and Rockville. Maryland, USA: CSA and ICF; 2016.

12 Nigussie J, Girma B, Molla A, Mareg M. Tetanus toxoid immunization Coverage and associated factors in Ethiopia : a systematic review and meta-. Res Sq. 2020;20:283.

$13 \mathrm{Kd} \mathrm{B}, \mathrm{Fy} \mathrm{T}, \mathrm{W}$ Td. Dropout rate of tetanus toxoid immunization and associated factors among reproductive age group of women in debrebirhan town. Amhara Journal of Women 's Health Care. 2017;6(4):4-11.

14 Gebremedhin TS, Welay FT, Mengesha MB, Assefa NE, Werid WM. Tetanus toxoid vaccination uptake and associated factors among mothers who gave birth in the last 12 Months in errer district, Somali regional state, eastern Ethiopia. BioMed Res Int. 2020:2020.

15 Kidane T. Factors influencing TTimmunization coverage and protection at birth coverage in TselemtiDistrict, Ethiopia. Ethiop J Health Dev. 2004;18(3):153-158.

16 Mamoro MD, Hanfore LK. Tetanus toxoid immunization status and associated factors among mothers in Damboya Woreda, Kembata Tembaro Zone, SNNP, Ethiopia. J Nutr Metab. 2018;2018.

17 Mihret MS, Limenih MA, Gudayu TW. The role of timely initiation of antenatal care on protective dose tetanus toxoid immunization : the case of northern Ethiopia post natal mothers. BMC Pregnancy Childbirth. 2018:1-10.

18 Anatea MD, Mekonnen TH, Dachew BA. Determinants and perceptions of the utilization of tetanus toxoid immunization among reproductive-age women in Dukem Town, Eastern Ethiopia : a community-based cross-sectional study. BMC Int Health Hum Right. 2018:1-10.

19 Mengesha Meresa Berwo,, Desta Abraha Weldegeorges, Natnael Etsay Assefa SGG, Hagos Degefa Hidru Ht and YH. Tetanus toxoid immunization status and associated factors among mothers in Abstract. Open Publ Health J. 2020;281-8.

20 Hashmi FK, Islam M, Khan TA, Tipu MK. Vaccination coverage OF mothers during pregnancy with tetanus. Pak J Pharm. 2011;24(2):35-39.

21 Naseem M, Khan MZ, Abbas SH, et al. Coverage and factors associated with tetanus toxoid vaccination among married women OF reproductive AGE : a cross sectional study IN peshawar. J Ayub Med Coll Abbottabad. 2010;22(June):136-140.

22 Kelem Desta Belihu FYT, TDW. Dropout rate of tetanus toxoid immunization and associated factors among reproductive age group of women in debrebirhan town , Amhara. J Women's Health Care. 2017;6(4):4-11.

23 Yaya S, Kota K, Buh A, Bishwajit G. Prevalence and predictors of taking tetanus toxoid vaccine in pregnancy : a cross- sectional study of 8,722 women in Sierra Leone. BMC Publ Health. 2020;1-9.

24 Roosihermiatie B, Nishiyama M, Nakae K. Factors associated with TT ( tetanus toxoid ) immunization among pregnant women, IN SAPARUA. SOUTHEAST ASIAN J TROP MED PUBLIC Heal. 2000;31(1):91-95.

25 Awosan Kj, Hassan M. Journal of Drug Delivery and Therapeutics Perception and utilization of tetanus toxoid immunization among pregnant women attending a tertiary centre in North-West Nigeria. J Drug Deliv Therapeut. 2018;8(6):119-124.

26 Vouking MZ, Tadenfok CN, Marie J, et al. Supplement article Review Strategies to increase immunization coverage of tetanus vaccine among women in Sub Saharan Africa : a systematic review. 2017;27(Supp 3):25-28. 
27 Khan Afridi Naseem, Juanita Hatcher SM, Dn. Coverage and factors associated with tetanus toxoid vaccination status among females OF reproductive age IN peshawar. JCPSP. 2005;15(7):391-395.

28 Stanley K, Diamenu, George Bosnu, et al. Introducing protection at birth (pab) method of monitoring tetanus-diphtheria (td) vaccination coverage of mothers in Ghana. Int J Vaccines Immun. 2015;1-4.

29 Beel ER, Rench MA, Montesinos DP, et al. Toward immunization during pregnancy and the peripartum period Knowledge and attitudes of postpartum women toward immunization during pregnancy and the peripartum period. Hum Vaccin Immunother [Internet]. 2013:5515. https://doi.org/10.4161/hv.25096. Available from:.
30 Haile Z, Chertok I, Teweldeberhan A. Determinants of utilization of sufficient tetanus toxoid immunization during pregnancy: evidence from the Kenya demographic and health survey, 2008-2009. J Community Health. 2012 Nov 18:38.

31 Anokye M, Mensah JA, Frimpong FO, Nicholas EOA, Acheampong. Immunization coverage of pregnant women with tetanus toxoid vaccine in Dormaa east districtbrong adaro region, Ghana. Math Theory Model [Internet]. 2014;4(6). Available from: http://citeseerx.ist.psu.edu/viewdoc/download?doi=10.1.1.919.9738\&rep=rep1 \& type $=$ pdf. 